\section{THE DEVELOPMENT OF SYNTACTIC COMPLEXITY IN THAI CHILDREN'S NARRATIVES}

\section{Suthasinee Piyapasuntra ${ }^{1}$}

\begin{abstract}
This article aims to present two essential points. Firstly, syntactic complexity value is an indicator of language development of children, especially in relation to narratives due to maturation and increased cognitive development. Secondly, complexity is measurable and assessable. This article argues that syntactic complexity as numerically measured has benefits for studying the close development of children in different age groups in which differences of language pattern and innovation may not be readily discerned. In order for a more accurate comparison between different age groups, the information employed was narratives of Thai children in the CHILDES database, Thai Frog Story series. The age groups were divided into 4 tiers: 4, 6, 9 and 11 years old respectively. Each group contained ten children which were compared to ten adults. The study found that syntactic complexity of children's narratives develops increasingly until it resembles to that of adults.
\end{abstract}

\section{Introduction}

Language development is a part of cognitive development (Piaget 1980, Clark 2003, Tomasello 2003), consequently, as children grow up, their potential to convey

\footnotetext{
${ }^{1}$ Assistant Professor, Department of Thai, Faculty of Liberal Arts, Thammasat University, Bangkok, Thailand
}

more complex stories should increase (Clark 2003). In studies of syntactic development, complexity has been frequently mentioned, albeit, with differing points of view (Lee and Canter 1971, Hirschman 2002, Rosenberg and Abbeduto 1987 cited in Charlton 2002). However, there have been no studies that accurately measure and assess narrative complexity in order to compare precisely between age groups (Charlton 2002). In the absence of such studies, complexity has been glossed by presenting differences in language patterns between each age group. If the samples belong to close age groups, however, differences in language patterns or innovation may not be detected. Conclusions may thus be drawn that children's language patterns do not become more complex or remain underdeveloped.

This article, therefore, aims to propose an approach for the assessment of syntactic complexity through the use of value in numbers for more precision in assessing complexity and more accuracy in comparison between different age groups. It article will consider whether complexity of language use relates to age of the language users, languages and importantly, language production process. It also aims to correlate these issues to difficulties that may occur in encoding and decoding processes or even in language acquisition and learning (Kusters 2003 cited in Miestamo 2008).

There are two essential points that this article focuses on Firstly, syntactic complexity value is an indicator of language development of children, especially in relation to narratives due to maturation and increased cognitive development. Secondly, this complexity is measurable and assessable. 


\section{Literature review}

\section{Narratives and syntactic complexity}

In order to narrate situations as a story, a narrator must possess knowledge in linguistic units containing meanings and syntactic tools to link those linguistic units as a story.

Clause is a linguistic unit showing a situation, composed of a verb indication a state or action and whatever participants are required by such verb. When situations are linked to narrative, the narrator will use a syntactic device to link these clauses into a unit called a complex sentence. In this research, a complex sentence also includes compound sentences in traditional terminology.

In relation to the narrator, Berman and Slobin (1994: 13) found that a skilful narrator would not separate each situation but would link all of them with syntactic mechanisms, resulting in a linguistic unit as large construction to convey the cohesion of the story. However, small children are not generally categorized as skilful narrators. Therefore, their narratives have special characteristics. Matthiessen (2002) found that clauses to compose larger units in children's language were not grammatical units but were emergent language patterns that were delivered without planning. As explained by Scott (1987 cited in Owens 1997), it has been found that the coordinator "and" occurs in $80 \%$ of children's sentences but that its use decreases markedly by the time they become teenagers around the age of 11-14 years old. Use of only $20 \%$ of "and" was found in teenagers' sentences in narratives with other kinds of coordinator used instead. As for this article, my research on syntactic complexity in Thai children narratives is in line with the referred research that the usage of coordination declines with children's maturation. This issue will be examined in the section "Results."

\section{The measurement of syntactic complexity}

Existing approaches to measuring syntactic complexity include a variety such as: simple measuring such as mean length of utterance (Scott and Stokes 1995, Voster 1988), focusing on the structure of linguistic units by the use of frequency count (Scott and Stokes 1995), count of ratio of target unit in discourse (Hirschman 2002 cited in Charlton 2002), and rating and assessment of complexity from tree diagrams showing sentence structure (Hawkins 2004).

Mean length of utterance (MLU) is used to measure the mean number of morphemes in 1 out of 100 utterances. Since this mean is in accordance with children's age and language development in other levels, this approach is popularly used for the measurement of language development (Scott and Stokes 1995, Vorster 1988). Nevertheless, it has been questioned if it can really reflect children's language development. It is widely acknowledged that sentences become longer as children age from kindergarten to primary school, but when they reach 9 until the beginning of their teenage years when growth in every aspect has become slower, no distinctive change has been detected.

In order to avoid this problem, some researchers try another approach such as counting the frequency of specific structures such as clause density considering ratio of 
subordinate dependent clauses per total number of clauses. For example, a ratio of 2.0 means a sentence comprises 2 clauses as main clause and minor clause, while a ratio of 1.10 means most sentences are simple sentences (Stokes 1990 cited in Charlton 2002). However, in order to be accurate, scope of counting must be clearly defined in terms of such things as morphemes or grammatical units. If the scope is not clearly defined, counts of the number of XS per unit risk becoming subjective (Charlton 2002).

Rosenberg and Abbeduto (1987 cited in Charlton 2002) divide sentences into 7 Developmental Levels comprising Level 1: infinitival complement clause, Level 2: coordinated subject noun phrase and coordinated clause, Level 3: relative clause modifying phrasal noun that is object or verb inflection of complement clause preceded by "that" all the way through to Level 7: the highest level of complexity. They contend that several different embedded clauses in a complex unit is the most complex structure imaginable. This approach seems to clearly grade complexity levels, however, it doesn't avoid the problem of scope defining.

In order to avoid subjective influences in, defining the scope of counter units, Lee and Canter (1971 cited in Charlton 2002), have developed a measurement system for syntactic complexity by setting up score systems of found linguistic patterns. This system is called Developmental Sentence Scoring (DSS) and focuses on syntactic development from the ages of 3-7 years. If sentence pattern appears, 1 score is given, 2 is awarded if pronouns are used, 3 is given if verbs are used, if there is a negative sentence, 4 is scored. 5 is given if a yes-no question is used, while a WHquestion earns 6 points, and 7 points is given if there is use of secondary verbs, embedded clauses, infinitival complements, coordinators or subordinating conjunctions. Lee and Canter found that the score becomes higher when children are more highly developed. Nevertheless, measuring tools to indicate whether sentence one is more complex than another is an interesting point of contention in the literature.

Another approach to explain complexity levels of structure is the use of tree diagrams since complexity is a function of structure that links terminal elements or words into sentences. The more components there are in the structure, the more linguistic categories required to be employed in language production (Hawkins 2004: 8).

Frazer (1985 cited in Charlton 2002) believes that characteristics indicating syntactic complexity can be gleaned from tree diagram complexity that indicates relations of sentence components. By counting the number of non-terminal nodes per terminal nodes found in one sentence making $\mathrm{s}$ and $\mathrm{s}$ bar higher than other non-terminal nodes, he could calculate the complexity.

For example, a sentence containing a complement clause such as "That John was sick surprises Sue" was considered to have a higher ratio of non-terminal nodes per terminal nodes compared to "It surprises Sue that John was sick." Although the subject "it" was used, the number of higher level structure remained the same. Therefore, the ratio is less. 

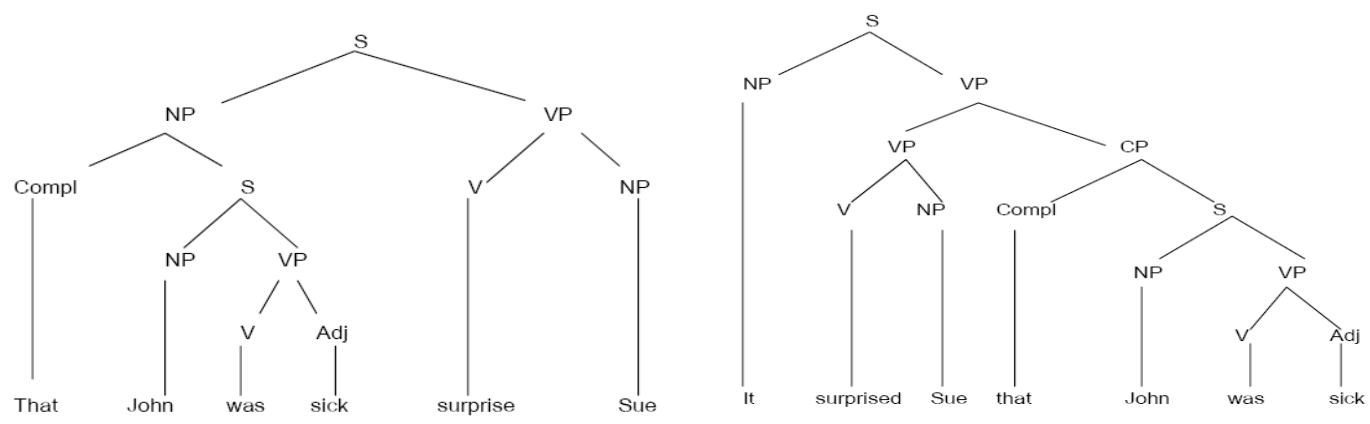

Figure 1: Tree diagram by John A. Hawkins (2004)

The above approaches are part of an attempt to explain syntactic complexity in the study of children's language development. Hawkins (2004) calculated complexity value from Non-terminal nodes per Terminal nodes and gave higher scores to $\mathrm{s}$ and $\mathrm{s}$ bar higher than other nodes (see figure 1. This approach makes the tree on the left hand side more complex than that on the right. The one on the left has eleven Non-terminal nodes per six Terminal nodes comprising one node as $\mathrm{s}$ and one node as $\mathrm{s}$ bar. The ratio is 13:6 or complexity degree of 2.16 . The tree on the right has thirteen Non-terminal nodes per seven Terminal nodes comprising one node as $\mathrm{s}$ and one node as $\mathrm{s}$ bar. The ratio is $15: 7$ or complexity degree of 2.14 .

A potential problem with this approach is that the researcher views syntactic complexity as the ratio of units to complex units but does not differentiate hierarchical relations that also affect the degree of complexity. The degree of complexity could be compared using mathematic calculation which would help make analyses more efficient.

Another problem is that the measurer does not consider complexity indicator units that have unclear scope such as the number of sentences per entirely of text. Selection of counter units to indicate complexity should be considered based on linguistic theory. Moreover, information to be measured should be stylistically scoped to prevent different results caused by other factors such as variable complexity of spoken and written languages.

This study, therefore, would like to present an alternative consideration of complexity based on ratio of units that is components of complex units having clear scope. Also it will consider differences in hierarchical relations and present calculation formula for complexity results based on objectivity in order to use the results for developmental comparison. The data used is already devoid of stylistic factors.

\section{Research methodology}

In this part, research methodology comprising data and analysis unit will be explained in more detail.

\section{Thai frog story: the comparable narrative data}

The story from a picture series "Frog: where are you?" in CHILDES database encourages 
readers to learn about events by viewing 24 pictures. (MacWhinney, B. 2000; Zlatev and Yangklang 2003) These pictures show a series of events that happen to three main characters, a child, a dog and a frog and that require a skilful narrator to link all the events into a story. Studying the information of this narrative should enable a comparison of syntactic structure development of narrators of different ages.

This article focuses on syntactic complexity in narrative of Thai children aged 4, 6, 9 and 11 years old and of adults, using as indicator the number of clause and clause linking via the use of syntactic mechanism into complex units. The research is conducted in the hope of being useful for teaching clause combination in text narrating to Thai children. Moreover, it is aimed to offer guidelines for developmental grammatical study in spoken language.

\section{Units of analysis and analysis methodology}

Main units used for study of syntactic complexity in this research are units of discourse with a linguistic pattern scope based on discourse index showing discourse fragment division or the beginning of new clause without clause linking units or that are not categorized as serial verb constructions.

(1) $\{[$ dèk kam-lạ nân moọ sù-nák]\} $\mathbf{0}\{[$ sù-nák kam-lạ duùm naám naj k $\hat{\varepsilon} \varepsilon w$ Child ASP. sit watch $\operatorname{dog} \quad \operatorname{dog}$ ASP. drink water inglass

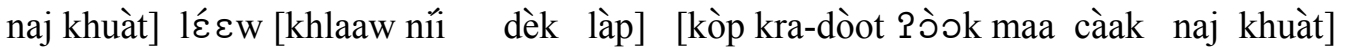
in bottle then time DEM child sleep frog jump out come from in bottle

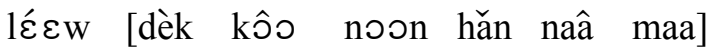

CONJ child CONJ sleep turn face come

[duu naj khùat] [sù-nák kôo khûn maa noon tháp]\} look in bottle dog CONJ up come lie on top

\{[dèk kam-lạ thòot muàk ?òok] lécw [dèk kôo Đəəj khún paj duu naj muàk Child ASP. take off hat out CONJ Child CONJ turn up go look in hat

[wâa mii ?a-raj rú-plàaw]]\} 3 \{[thii niii dèk pə̀ət naâ-taàn maa duu] COMPL. has anything YES-NO P. time this child open window come see

[su-nák kôo Paw khuàt khrô̂p húa wáj] lécw [dèk kôo phlòo maa duu] dog CONJ take bottle cover head ASP. CONJ. child CONJ show come see 


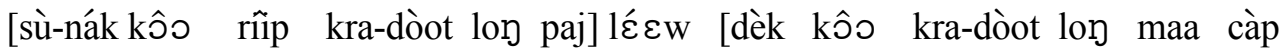
Dog CONJ hurry jump down go CONJ. child CONJ. jump down come catch

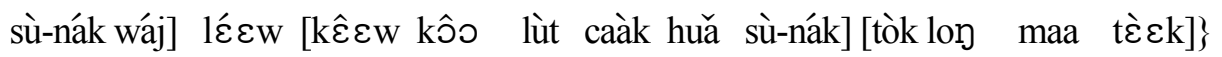
dog ASP. CONJ. glass CONJ. fall from head dog fall down come breaks

$\{[$ dèk kam-lạ làp taa]\} [06A1-18]

Child ASP. close eyes

$\{[A$ child is sitting watching the dog]\} $\boldsymbol{O}\{[A$ dog is drinking from a glass a bottle] then [this time, the child sleeps] [A frog jumps out of the bottle] then [The child lies turning his face][looks in the bottle] [The dog lies on the top]\} 2 \{[A child is taking off a hat] then [The child tilts up his head to look in his hat] [to see if there is anything inside]\} $\boldsymbol{B}$ \{[Now, the child opens the window to see] [The dog covers its head with the bottle] then [the child turns up to see] [the dog hurries to jump down] then [the child jumps down to catch the dog] then [the glass falls off the dog's head] [and breaks]\} $\boldsymbol{\Theta}$ \{[The child closes his eyes]\} [06A1-18]

The example above suggests that 123 and $\mathbf{4}$ are positions without linking by any syntactic mechanism which in this research is counted as scope of discourse unit symbolized by $\{.$.$\} . (Please note that [.$.$] is$ for clause boundary. [/] is for repetition.)

Units of discourse in this study are divided into 2 types: firstly, simple unit which is a sentence comprising one clause without any dependent clause or down grading clause presenting one proposition that may be separated by a pause with one speech act, secondly, complex unit, which is a unit of narrative having a pattern of discourse. Most simple units found in the studied narrative are serial simple unit construction and are mostly separated by complex units. Example (2) below shows nine simple units in a serial construction.

(2) $\{[$ mii dèk $]\} \quad\{[$ mii măa $]\}\{[$ mii kòp $]\}\{[$ mii phra-can $]\}\{[$ mii faj $]\}$ have child have dog have frog have moon have fire

$\{[$ mii tian $]\}\{[$ mii phaâ-chét nâa $]\}\{[$ dèk noon $]\}\{[$ kòp kra-dòot $]\}$ [04B1-9] have bed have handkerchief child sleep frog jump

$\{[$ There is a child] $\}\{[$ There is a dog]\} \{[ There is a frog]\} \{[ There is the Moon]\} \{[ There is a lamp]\} \{[ There is a bed]\} \{[ There is a handkerchief]\} \{[A child sleeps]\} \{[A frog jumps]\} 
The above example is from a child aged 4 narrating two serial pictures. The child described entities and actions of participants without linking such events. A number of simple unit constructions in sequence are always found at the beginning of narratives and especially in small children aged 4-6 but these are not found in adults
As for complex units in the narratives, several patterns were found whether being linked by the same and different syntactic mechanisms, linked by the same syntactic mechanism or being a series of clauses linked by the transitional words $k \hat{\jmath} \supset$ "then" or "and then" as in example (3) below.

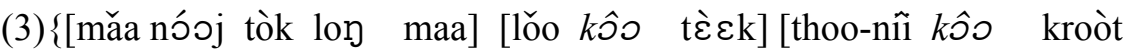
dog little fall down come jar CONJ. break Tony CONJ. angry

mǎa nóoj] $\}[11 \mathrm{D} 25-27]$

dog little

\{[The little dog then falls] [the jar is then broken] [Tony is then angry with the little dog]\}

The above example was given by an 11year-old child using the transitional word $k \hat{o} \supset$ "then" in the second and third clauses signifying a balance of linkage between it and the preceding clause of a coordination type.

Moreover, there are complex units created by placing clauses in sequence in subordination type that are linked by subordinators mûâ "when" and curg "since". While the complex units created by clauses placed in sequence through embedding are always linked by complementizer thî̀/wâa "that" or relativizer thî̀/ sû̀/ Pan that" or "which". The other complex units are made through serial verb constructions.

\section{Results}

The pilot study on syntactic complexity in Thai children's narratives found that the majority of complex units are linked with diverse syntactic mechanisms. From my research, 11 patterns have been found: Pattern 1 \{coordination+subordination\}, Pattern 2 \{coordination+subordination+ embedding\}, Pattern 3 \{coordination+ subordination+embedding + serial verb construction\}, Pattern 4 \{subordination +embedding\}, Pattern 5 \{subordination+ embedding + serial verb construction $\}$, Pattern 6 \{embedding+serial verb construction\}, Pattern 7 \{coordination+ subordination+serial verb construction $\}$, Pattern 8 \{coordination+serial verb construction\}, Pattern 9 \{coordination+ embedding\}, Pattern 10 \{coordination+ embedding + serial verb construction $\}$ and Pattern 11 \{subordination+embedding+ serial verb construction\}. However, the range of links is not limited to this number. An interesting point to explore is the order of such links.

Moreover, it is found that the usage of coordination has declines with age while the use of other connectives rises. 


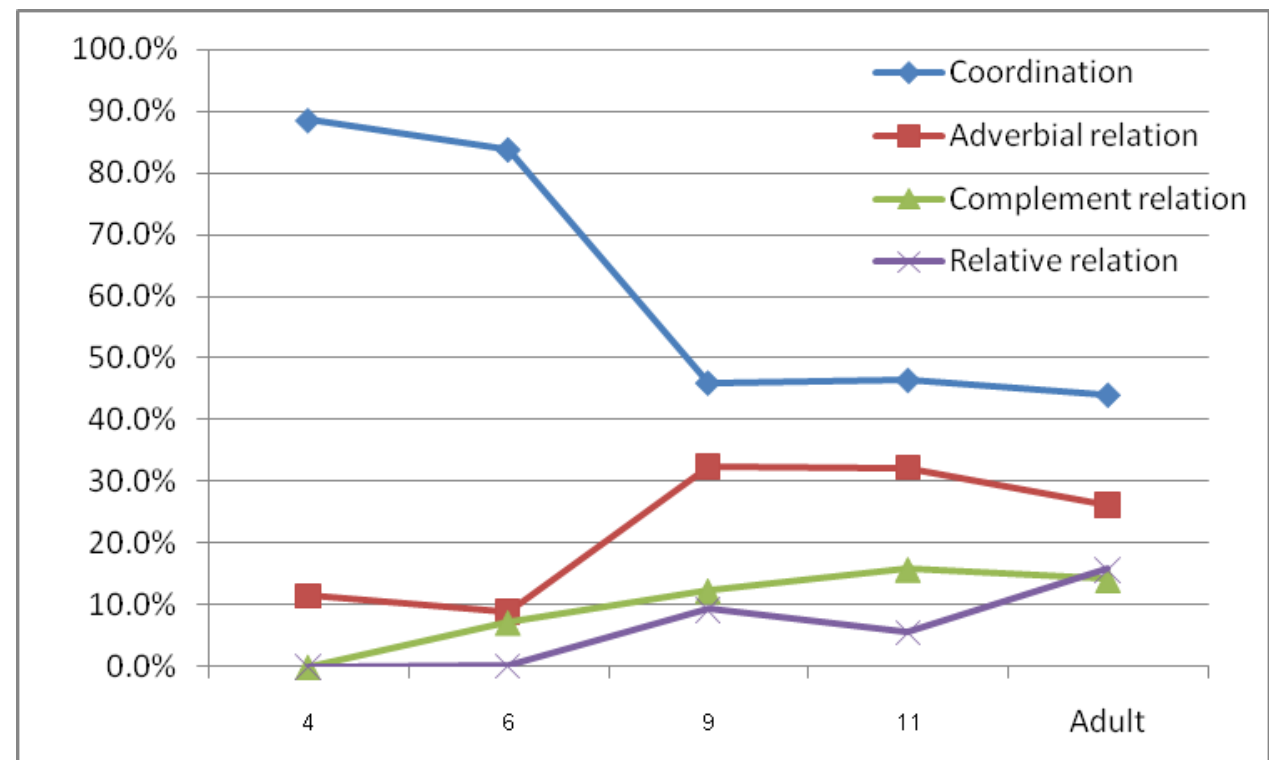

Figure 2: Types of complex sentence

Figure 2 shows that children of 4 years use coordination at the rate of $88.5 \%$ of the narratives, children of 6 years use $83.8 \%$, children age 9 use $46 \%, 11$ use $46.4 \%$ and adults use $44 \%$, while other relations all increase.

Nevertheless, counting only the number of clauses with different kinds of relations may not efficiently show the overall picture of complexity from the point of view of text structure. Measuring syntactic complexity of linguistic units that are larger than clauses is indispensable and needs to be precisely done. It is considered that in terms of narrative process, complex description for the whole structure of the text is key. This article believes that a study of complex unit structure could portray the whole structure of the text.

In what follows, complexity measured from the structure of complex units in Thai children's narratives will be explored. The subject will be divided into overall complexity of narrative text and complexity value of complex unit in details.

\section{Complexity measured from structure of complex unit in thai children narratives}

Study of structural complexity in this research relies on 2 descriptive parts. Firstly, complexity of narrative text is studied via the overall picture of the text narrated by a child considering ratio of simple units per complex units in a story. Secondly, complexity in structure of each complex unit is studied by creating tree diagrams. The complexity may be discerned via the pattern of the tree diagram in terms of whether it is a horizontal tree or a vertical tree. Moreover, complexity can be calculated numerically for comparison among age groups, thus enabling a more accurate assessment of the complexity in which subjectivity is reduced. 


\section{Overall complexity of narrative text}

From 50 narrators, there was a total of 1,693 units of discourse fragment categorized as 799 simple units $(47.19 \%)$, and 894 complex units $(52.81 \%)$. In terms of information between children and adults, the rate was equivalent. From children's narratives, $47.73 \%$ was simple units and $52.27 \%$ was complex units while adult narratives comprised simple units of $46.25 \%$ and complex units of $53.75 \%$. Although, the complex unit ratio was higher, it was still very close. From this point of view, it can be concluded that children's and adults' narrative complexity was similar.

However, if considered by age, it was found that children aged 9-11 and adults made use of complex units more than simple ones, while children aged $4-6$, on the other hand, made greater use of simple units. It could be concluded that the description of complexity with the ratio of units of discourse shows language ability development to a certain extent.

\section{Deeper analysis of complexity value of complex units}

In this section, simple units are not taken into account. The focus of analysis here are complex units created by the researcher who divided the text into units based on criteria of syntactic linkage. The linked clause clusters are analyzed in terms of hierarchical relations and presented via a tree diagram. It is believed that such an approach offers strong potential for understanding and producing the complexity of the narrator to place information in order and transfer it to the receiver.

Normally, the number of constituents in a unit indicates complexity; that is, the higher the number, the more complex the unit becomes. However, with complex units in narratives that are focused on the number of clauses, it is found that if two units have the same number of clauses, the tree diagram must be used since it gives information in terms of hierarchical relations of such components.

Analysis of complex unit structure using tree diagrams shows hierarchical relations of clauses in terms of coordination and serial verb construction. To decide which clauses relate most fully to each other, meaning and syntactic characteristics are used. Therefore, it is possible that a tree diagram can show subordination at levels higher than coordination. For example,

(4) [[[câw dik-kîi son] lé? [sûm-saâm]] [con tham hâj khuàt tôn tè غk]] Fellow Dickey naughty and careless so make bottle must broken

[[[Dickey is naughty] and [careless $]]$ so the bottle is broken $]]$ 


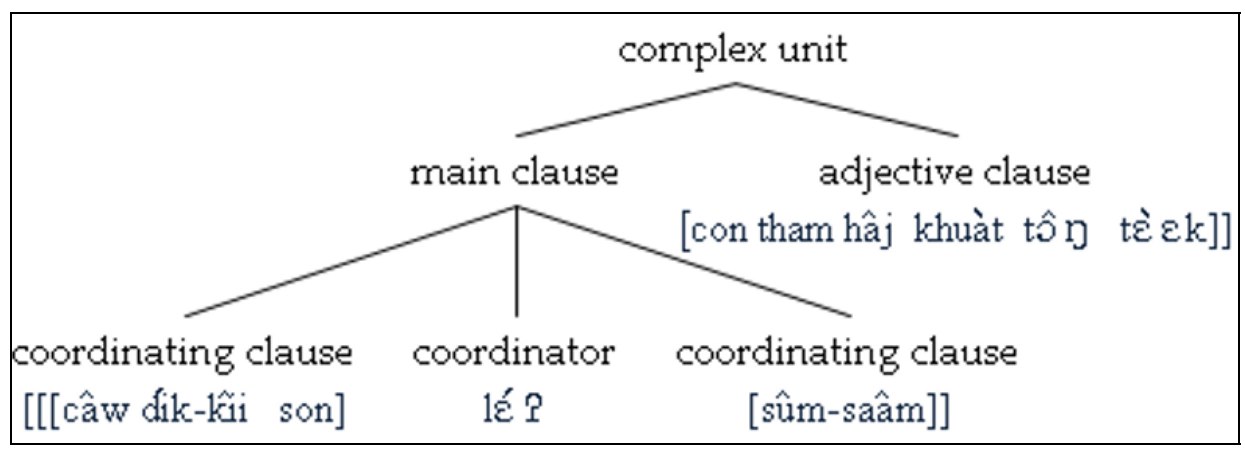

Figure 3: Chart showing structure of complex unit

\section{Significance of tree diagram characteristics and levels of complexity}

This section considers the number of levels and nodes at second level. Testing some information showed that the number of levels varies according to complexity value, while the number of clauses in the second level nodes of complex unit will be in reverse variation. Briefly, if the number of clauses in the second level node of complex unit is low, the value of complexity will be high because the tree diagram becomes more vertical. Thus, number of levels becomes higher and more complex (see figure 3).

For the same reason, it can be concluded that the shape of the tree diagram showing each type of complex unit structure signifies complexity to different degrees. A horizontal tree shape is a tree with one level as shown in example (5) and figure 4.

(5) [dèk tòk phwún] [hวつ-nók- huûk kôo ləəj [/] həว-nók-huûk kôว ləəj Child fall floor owl CONJ. so owl CONJ. so (1) 2

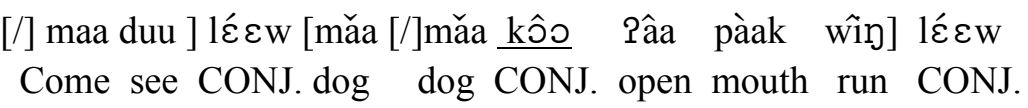
3

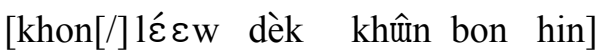
Man CONJ. child get on on rock 4

\{[A child falls on the floor]lthe owl then, the owl then []comes to see ][and then the dog [] the dog then opens his mouth and runs] [then a man[] then the child gets on a rock] \} 
The clauses (1), (2), (3) and (4) are linked by the coordinating conjunctions "then" and "and then" showing relations between of the four clauses at the same level. They are neither dependent nor subordinating clauses in structure. The tree diagram consequently at a horizontal level as follows:

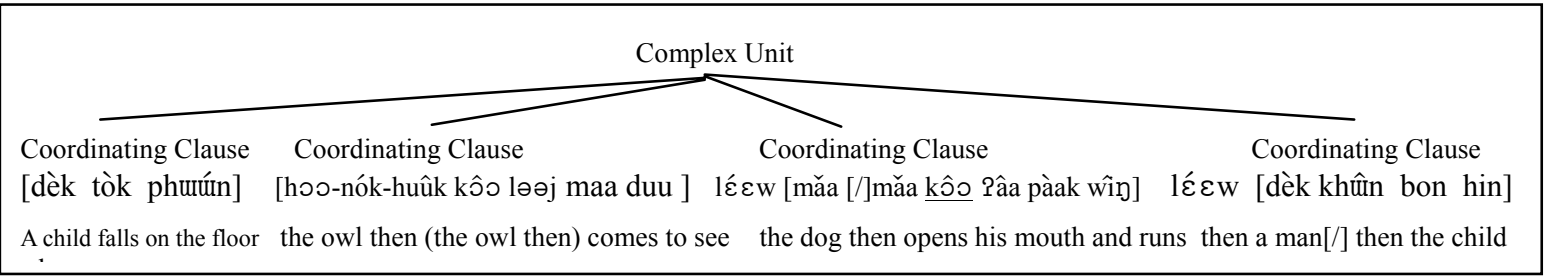

Figure 4: Tree diagram showing structure of sampling complex unit

A vertical tree shape is a tree diagram having two levels or more. This kind of diagram, although without many clauses, will, if it has a small number of nodes, still have several levels resulting in more complexity than a counterpart having only one level. The following example (6) of a vertical tree shape has the same number of clauses as the previous example but a different number of levels, namely an additional level.

(6) $\{[[$ mii kòp tua nùn] [jùu kàp mǎa]] lé $\varepsilon w$ [[mii dèk] Have frog CLASS one be with dog CONJ. have child (1

[kam-lan noon]]] \} [04I1-4]

ASP. lie

4

$\{[[$ There is a frog] [being with a dog]]then[[There is a child] [ sleeping]]] \}

The pair of clauses (1) and (2) are in a serial verb construction, and (3) and (4) are in different serial verb constructions. The two serial verb constructions are linked with the coordinator "then" indicating coordination. The hierarchical relation can be analyzed as a tree diagram having two levels of nodes in vertical direction as shown in figure 5 . 


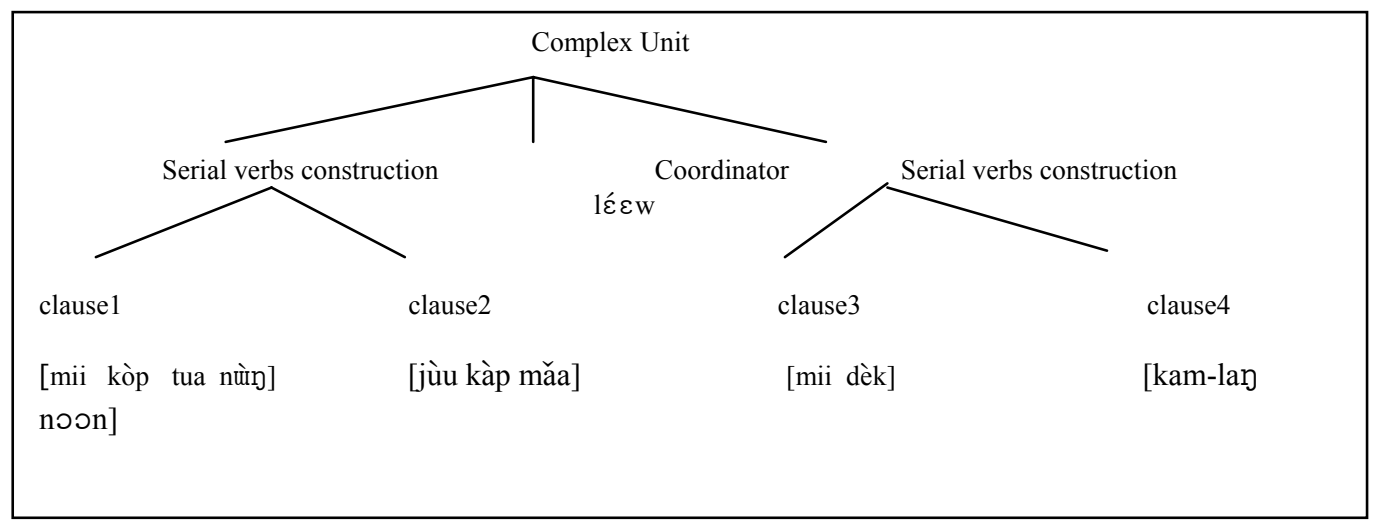

Figure 5: Tree diagram showing structure of sampling complex unit

In summary, a vertical-shaped tree is less complex than the horizontal counterpart. As a result, figure 4 is less complex than figure 5 .

\section{Calculation of complexity value}

In this section, calculation methods will be discussed in terms of applicability for each form of tree diagram and efficiency in showing difference of complexity on an actual basis.
If comparing the vertical and horizontal tree shapes outlined in the previous section, a good formula should show that the tree diagram in figure 4 has less complexity. This is because there is only one level nodes while hierarchy is detected in the tree diagram in figure 5 , although having the same number of clauses as figure 4 . Therefore, a good formula must show different results.

The formula presented in this research is as follows:

Complexity Value $=$

No. of Clauses in a sentence X No. of Levels of tree diagram

This formula, when calculated using the horizontal tree shape in figure 4, will give 1 as a result, regardless of the number of clauses the tree has. Such a result is acceptable in this research since the linking of clauses of the horizontal tree shape does not have a hierarchical relation.
No. of second level nodes

The number, therefore, will not show hierarchy. If wanting to find complexity in terms of number of clauses, counting should be chosen without calculation using this formula. The result is now appropriate and when compared to figure 5, this formula will render a greater complexity 
value of $(4 \times 2) \div 2=4$, which means this formula can point out differences between the horizontal and vertical tree shapes.

Moreover, this formula shows the distinctiveness of vertical tree shapes that have different level numbers. When using this formula with the vertical tree shapes that have two or more levels, it will give different complexity values.
Now, two complex units each containing four clauses are being compared. However, the tree diagram shows that one unit has two levels of nodes while the other has three levels of nodes, as seen when comparing figure 5 and figure 6 as follows:

(7) \{[dèk chaaj dəən Pòok paj thîi chaaj paà] lécw [róon ta-koon bòok câw kòp] Child male walk out go at edge wood CONJ. yell shout tell fellow frog (1)

[[waa câw kòp khaâ jaàk hâj] [câw klàp maa]\} [09B22-25]

COMPL. fellow frog I want fellow back come 3

\{[The boy walks into a wood] then [yells saying that the frog!] [[The frog I want] [you to come back]\}

This example has three levels of nodes since there are clauses relating in the manner of a serial verb construction (Clause 3 and 4 ) in the complement clause starting with "that." When adding clause 2 , it is combined as a coordination clause relating to clause 1 .

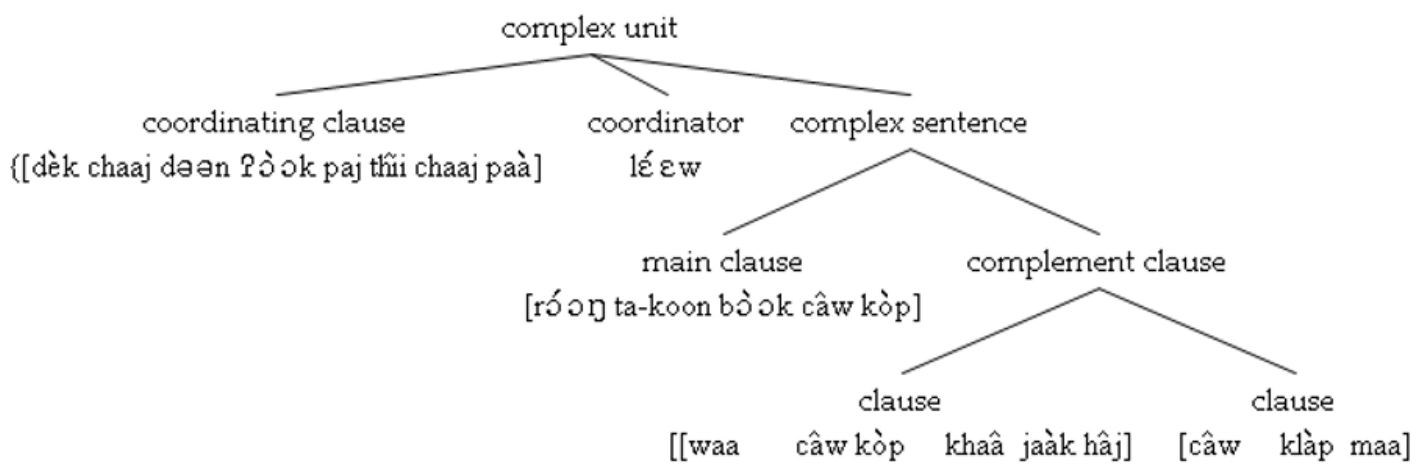

Figure 6: Tree diagram showing structure of sampling complex unit 
If applying the formula presented in this article with the same case study, the result of the complex unit having 2 complexity levels is $(4 \times 2) \div 2=4$ as in figure 5 compared with the result $(4 \times 3) \div 2=6$ as in figure 6 . It is thus found that complexity value will be in actual order of complexity value.

Other calculation methods may not give as good a result. For example, dividing the number of clauses with the number of levels cannot give an accurate value for a tree shape with deeper node levels.

\section{Analysis Result}

For the presentation of results, the researcher would find the mean of complexity result from complexity unit calculation for each age group. Studying five age groups of narrators indicates that complexity value has increased in line with higher age as can be seen in figure 7 .

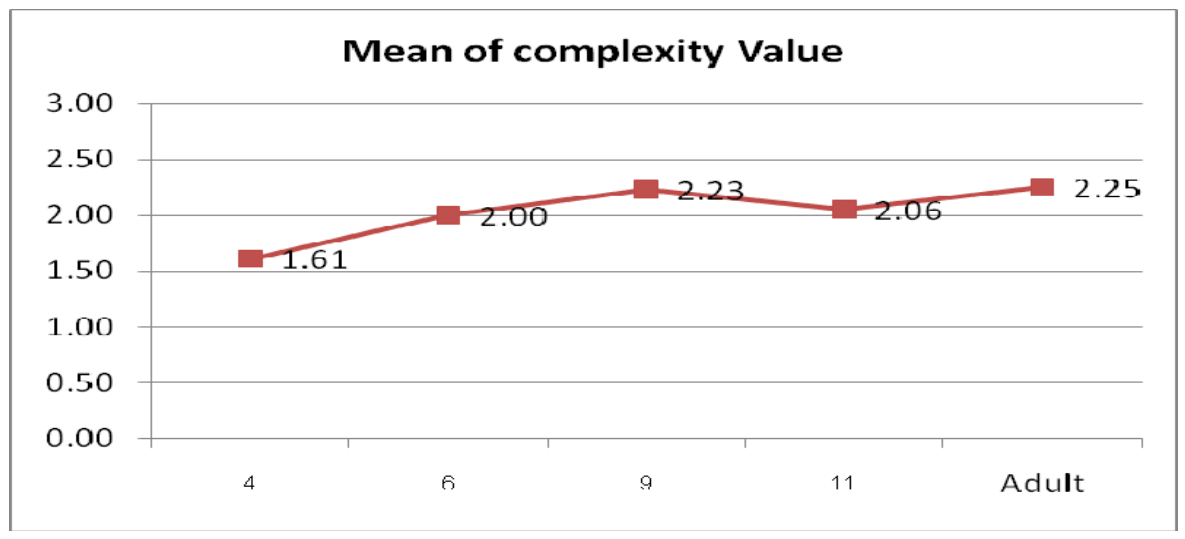

Figure 7: Mean of syntactic complexity value in each age group

It was found that children aged 4 had a lower mean of 1.61 , while the complexity value increases with age, with children aged 6 was 2, aged 9 at 2.33. And although the result for those aged 11 is slightly decreased to 2.06 , it is not obvious. However, the-complexity value of children from age 9 was similar to that of adults at 2.25 .

The complexity value found showed that change in the value reflected development of each age and could explain linguistic phenomenon in terms of language perception and learning that will be later explained.

\section{Conclusion}

Development occurs as an attempt to communicate. In order to narrate a number of combined events, children must learn about rational and temporal relations. Also, they must acquire knowledge to 
arrange the information into a structure. They must know which information is a main clause or minor clause and know how to link two (or more) clauses (Clark 2003).

As a result, to study syntactic complexity in Thai children's narratives, a researcher needs to see the overall picture of complexity of a unit as a unit occurring in discourse. Importantly, a tool must be created to measure complexity as compared among age groups and examine children's development. This article has presented two key points dealing with the development of complexity units and an alternative measuring method for complexity and comparison among age groups.

As for development of complex units, the research found that use of complex sentences, as defined by the research, can be found in four-year-old children. In previously conducted research, Diessel (2004) found that small children start making use of complex sentences at the age of 2 years old and are able to command a variety of sentences. The found pattern starts from (1) complement-taking verb "wanna" followed by infinitival verbs and not long thereafter children can coordinate clauses with "and." A few months later, they can start using (2) complement clauses, verb inflections followed by (3) a complement clause that always co-occurs with a matrix clause. After that, they can use (4) clausal and adversative clauses linked by "because", "but" and "so" followed by (5) relative clause modifying nouns preceded by copular verbs or noun phrases.

The sequence of such patterns is in line with the amount of information used in the research. The database used in the research started with children aged 4 since the children are required to narrate a story first. Thus, no primary development has been noticed but it could be supplemented to see development after two years old in a compatible way. Children aged four still use patterns that they have initially developed, mostly coordination clauses such as léعw "and". Secondly, they have developed the use of complement clauses with a slight use of adjectival clauses. However, no relative clauses are found in children at this age. Moreover, only single clause structures are found in children at age six.

Coordination is where complex units are created by placing clauses in sequence in order to foreground meaning. This type of complexity unit happens a lot in the narration of serial events and pictures; the simplest way is to show equal relations between those events in chronological order.

The most commonly found complement clause is that which co-occurs with a verb of saying. Moreover, adjectival clauses function as a modifying unit complementing the main clause in terms of time, place, manner, purpose, reason, circumstance, simultaneity, condition, negative condition, concession and result like function of adjective. All of these are for background linking and children will start to use them when they have grown up.

As for measuring syntactic complexity, there are different points of view ranging from measuring the average length of utterance, and counting ratios in several types of structure. However, boundary setting is a problem. The measuring unit categorizes sentences into seven levels based on complexity, while defining the score weights of language patterns is difficult to achieve with precision in language pattern complexity. Tree diagrams 
showing sentence structure should be more accurate but these have not been extended scope to cover units larger than a sentence. As a result, they cannot be used comprehensively to study narratives.

This article, therefore, depends on ratio of units that are components of complex units paying attention to precise boundary setting of such components such as clauses and units of discourse comprising simple and complex units. This complexity measuring does not view only one aspect such as ratio, but also encompasses hierarchical relations that will be useful for showing structural complexity in every dimension. Study results from this calculation formula can inform numerical levels of complexity to be used for comparison in terms of development.

Complexity degree tends to increase in children between the ages of 4-9 years but no obvious tendency can be predicted after that. It can be concluded that syntactic complexity concerning tree structure obviously shows complexity units in children until they reach age 9. As for children of 11 years old and adults, development has slowed down. There is no significant difference between children of age 9 and adults.

Moreover, it can be noticed that children of age 11 have less complexity. When focusing on relations of clauses, it is found that coordination has slightly increased from children of age 9 (see figure 2). This may cause the complexity of children of age 11 to be slightly less than their 9-yearold counterparts.

However, from close observation, it is noticed that children aged 11 have pragmatics similar to that of adults in terms of role playing and narrative stylistics. The narrator will narrate the story in a simple way as if he narrated it to a child. This issue may affect the similarity of complexity of children aged 11 and adults. As a result, study of the linguistic development of children aged 11 compared to adults should be examined in more detail.

A more interesting point is the obvious development of a tree structure that clearly shows complexity units in children of age 4 and 6 . Those of 6 years old have higher complexity value by 0.39 than those of 4 years old, much higher than other groups of close age range. This is possibly because 6 is the age to start education at school where they have a chance to learn a lot of syntactic knowledge very quickly.

Study of syntactic complexity in Thai children's narratives indicates the complexity's compliance with the ages of the narrator and so it may be concluded that complexity is an indicator of development. Moreover, in terms of potential benefits, this study offers an approach to discover new methods for studying syntactic complexity. Furthermore, in terms of application, the perspectives advanced in this article may support new understandings of spoken language grammar in terms of descriptive method or applications for teaching language to children.

\section{References}

Berman, Ruth Aronson and Dan Isaac Slobin. 1994. Relating Events in Narrative : a Crosslinguistic Developmental Study. Hillsdale N.J: Lawrence Erlbaum Assocates. 
Clark, Eve V. 2003. First Language Acquisition. Cambridge : Cambridge University Press.

Charlton, Bruce G. 2002. Language Complexity, Working Memory and Social Intelligence. UK: University of Newcastle upon Tyne.

Hawkins, John A. 2004. Efficiency and Complexity in Grammars. New York: Oxford University Press.

MacWhinney, B. 2000. The Childes Project: Tools for Analyzing Talk. $3^{\text {rd }}$ edition. The Database, Volume 2. Mahwah, NJ: Lawrence Erlbaum Associates.

Matthiessen C.M.I.M., 2002. Combining clause into Clause Complexes: A Multi Faceted View in Joan Bybee and Michael Noonan eds. Complex Sentences in Grammar and Discourse Essays in honor of Sandra A. Thompson University of New Mexico University of Wisconsin at Milwaukee. 235-320.

Miestamo, Matti, Kaius Sinnemäki and Fred Karlsson (eds.). 2008. Language complexity: Typology, contact, Change (Studies in Language Companion Series 94). Amsterdam: Benjamins.

Owens, Robert E. 1997. Language Development : An Introduction. NewYork : Macmillan.

Piaget, Jean and Noam Chomsky. 1980. Language and Learning / The Debate between Jean Piaget and Noam Chomsky. Cambridge : Massachusetts, Harvard university Press.
Scott, Cheryl M. and Sharon L. Stokes. 1995. Measure of Syntax in School Age Children and Adolescents. In Language Speech and Hearing Services in School. Vol. 26: 309-319.

Tomasello, Michael. 2003. Constructing a Language: a Usage-Based Theory of Language Acquisition. Cambridge, Mass: Harvard University Press.

Vorster, Jan, 1988 Paraphrasing Extending the Database for Child Language Research, Language Science. Volume 10, Number 1: 173-192

Zlatev, J. and P. Yangklang. 2003. Frog Stories in Thai: Transcription and Computerised Analysis of 50 Thai Narratives from 5 Age Groups. Submitted to Journal of Child Language. 